\title{
EL PRIMORRIVERISMO VALENCIANO: ORIGEN Y FUNCIONAMIENTO DE SUS ÉLITES MILITARES (1923-1930)
}

\author{
Julio López Iñíguez. \\ Universidad de Valencia
}

\begin{abstract}
Resumen: El golpe de estado de Primo de Rivera en septiembre de 1923 supuso una importante división del ejército en la provincia de Valencia. Gran parte de los mandos castrenses provinciales y regionales apoyaron el pronunciamiento, pero acabaron enfrentados al capitán general de la región militar. Tras esta tensión inicial el dictador consiguió crear una red de oficiales afines que dirigieron las principales instituciones militares en Valencia. La disciplina y jerarquía del Ejército español se transmitía así a la administración valenciana mediante tácticas clientelistas.
\end{abstract}

Palabras clave: dictadura de Primo de Rivera, militarismo, autoritarismo, jerarquía militar, clientelismo.

The dictatorship of Primo de Rivera in Valencia: origin and fuctioning of its military elites (1923-1930)

Abstract: Primo de Rivera's coup d'état in September 1923 was an important division of the army in the province of Valencia. Most of the provincial and regional military commanders supported the coup but ended up confronting the commander in chief of the military region. After this initial tension, the dictator managed to create a network of related officers who led the main military institutions in Valencia. The discipline and hierarchy of the Spanish Army was thus transmitted to the Valencian administration by means of clientelist tactics.

Key words: Primo de Rivera's dictatorship, militarism, authoritarianism, military hierarchy, patronage.

\section{EL PLANO INCLINADO HACIA EL GOLPE DE ESTADO}

Los acontecimientos de la época de entreguerras europea (1914-1945) tuvieron en España uno de sus escenarios principales. A pesar de su neutralidad durante la I Guerra Mundial, España tuvo que sufrir varios golpes de estado y una cruenta contienda civil, con unas consecuencias humanas y materiales de proporciones gigantescas. La primera de las dos dictaduras a las que tuvo que hacer frente la nación española conllevó un caudillaje bastante común a los re-

Data de recepció: 24 de juliol de 2018 / Data d'acceptació: 4 d'octubre de 2018. 
gímenes conservadores y autoritarios europeos del momento (Traverso, 2009, 86). Aspectos como la dominación carismática y una voluntad de salvador providencial pueden aplicarse perfectamente al líder que gobernó España entre 1923 y 1930: el general Miguel Primo de Rivera.

Los pronunciamientos militares del siglo XIX en España tuvieron continuidad en el primer tercio del siglo XX (Santacreu Soler y Pérez Herranz, 2000, 183). La garantía canovista del civilismo había fracasado por completo desde los acontecimientos de 1898. La presencia del ejército en los asuntos de gobierno se acrecentó tras la desaparición de Cánovas y el desastre colonial (Seco Serrano, 2000, 285). Además, la neutralidad de España en la I Guerra Mundial provocó grandes cambios económicos que, en pocos años, conllevaron la ruina del sistema restauracionista. Ni siquiera la modernización conservadora fue capaz de hacer frente a tal desafío (González Cuevas, 2008, 41). A corto plazo el desorden económico provocado por las exportaciones a los países beligerantes originó una creciente oleada de violencia, sobre todo en Cataluña. Esta violencia favorecía la crónica presencia de interferencias militaristas (González Calleja, 1999, 258). Esta doble confluencia de crisis económica y política ya fue analizada detenidamente por la historiografía clásica sobre el período posterior a $1923^{1}$.

Las continuas demandas de democratización tampoco fueron atendidas correctamente. A las leyes de 1890 y 1907, que podían haber supuesto una participación efectiva de los obreros y los campesinos en los resultados electorales, se contraponían limitaciones de partida no despreciables que afectaban a la transparencia a lo largo de todas las fases de los comicios (Carnero, 1997, 220221). Para profundizar en este sentido hubiera sido necesario el final de una concepción elitista de la política y la aceptación de la participación de las masas (Barrio, 2006, 155). Sin embargo la solución planteada por los dos partidos dinásticos referente a un gran consenso nacional tampoco funcionó (Martorell y Juliá, 2012, 230-232). Un episodio de violencia política como el asesinato de Eduardo Dato en marzo de 1921 se sumaba a las responsabilidades de Marruecos tras el desastre de Annual (Cabrera, 1998, 96). En esta convulsa situación la investigación de la comisión Picasso supuso algo más que un trámite sancionador. El informe del general Picasso empezó a amenazar tanto al gobierno de Sánchez Guerra como al propio Alfonso XIII (Cabrera, 2003, 106).

${ }^{1}$ Ben-Ami, S. (1983): La dictadura de Primo de Rivera (1923-1930), Barcelona, Planeta, 325 p.; González Calbet, M. T. (1987): La dictadura de Primo de Rivera: el Directorio militar, Madrid, El Arquero, 290 p.; Gómez-Navarro, J. L. (1991): El régimen de Primo de Rivera: reyes, dictaduras y dictadores, Madrid, Ediciones Cátedra, 553 p. 
El general Primo de Rivera, a pesar del descrédito inicial que tenía en algunos círculos castrenses españoles debido a su postura abandonista en Marruecos, contaba con fuertes apoyos entre los principales representantes de la burguesía catalana de cara a una posible solución autoritaria (Preston, 2006, 72). Algunos historiadores han calificado al dictador como una persona de carácter bronco y conflictivo (Tusell y García Queipo de Llano, 2001, 422). Pero lo cierto es que ese talante autoritario le valió el apoyo burgués catalán antes comentado en su etapa como capitán general de Cataluña (González Calleja, 1999, 262). La efectividad demostrada durante la represión de los disturbios barceloneses posteriores a 1919 inició un proceso de carismatización que le habilitó para un ejercicio autoritario del poder (Quiroga, 2013, 149) ${ }^{2}$.

El papel del monarca en los preparativos del golpe ha sido muy discutido, siendo muy complicado demostrar la relación entre la comisión Picasso y el pronunciamiento (Martorell y Juliá, 2012, 236-237). El propio Alfonso XIII se esforzaba en defender su nula vinculación con la asonada al cónsul británico en San Sebastián al afirmar que no tuvo previous knowledge of military coup, the four Generals who were leaders having kept king ignorant in order that if it failed he might feel at liberty to agree to any punishment that might be inflicted on them ${ }^{3}$. En general la historiografía más reciente y especializada ha incidido en la campaña de desprestigio que para Alfonso XIII supuso la sanción del nuevo régimen, sobre todo por parte de intelectuales (Moreno Luzón, 2003, 27).

\section{EL GOLPE EN VALENCIA}

El papel de la provincia de Valencia en el golpe de estado de 1923 merece ser destacado. Los progresivos estudios locales o regionales en España nos han permitido conocer en detalle aspectos relevantes del acontecimiento ${ }^{4}$. No sólo

${ }^{2}$ Del mismo autor, y clave para entender la dictadura, Quiroga Fernández de Soto, A. (2008): Haciendo españoles: la nacionalización de las masas en la dictadura de Primo de Rivera (1923-1930), Madrid, Centro de Estudios Políticos, 383 p.

3 The National Archives, sección Foreign Office, W 7430. El telegrama está registrado con fecha de 21 de septiembre de 1923.

${ }^{4}$ Entre las obras más destacadas para el resto de España encontramos la de Ponce Alberca, J. (1999): Política, instituciones y provincias: la Diputación de Sevilla durante la Dictadura de Primo de Rivera y la II República (1923-1936), Sevilla, Diputación de Sevilla, 783 p.; Fuente Langas, J. M. (1998). La Dictadura de Primo de Rivera en Navarra, Pamplona, Gobierno de Navarra, 609 p.; Fernández Clemente, E. (1996): Gente de orden: Aragón durante la Dictadura de Primo de Rivera, 1923-1930, Zaragoza, Caja de Ahorros y Monte de Piedad de Zaragoza, Aragón y Rioja, 403 p. 
por las divisiones existentes en el seno de los mandos militares a raíz de la asonada del 13 de septiembre de 1923, sino también por la gestación de una nueva élite militar que dirigió la provincia valenciana hasta 1930. La situación política valenciana previa a la llegada al poder del general Primo de Rivera no había registrado novedades de interés. El gobernador civil de la provincia, Javier Cabello Lapiedra, venía ocupando el cargo desde el 12 de diciembre de 1922. En febrero se había producido un cambio en la alcaldía de Valencia que, tras los desacuerdos entre las diferentes fuerzas políticas, iba a recaer en Juan Artal, albista, en detrimento del conservador Albors. La noticia iba a tener una repercusión negativa en la mayoría republicana del ayuntamiento, que expresó su malestar en la toma de posesión del nuevo alcalde.

Las elecciones de diputados del 29 de abril, de senadores el 13 de mayo y de diputados provinciales el 12 de junio fueron bastante ajustadas, siendo lo más destacado de ellas las protestas de varios candidatos ante los resultados y la división de los conservadores en diferentes facciones. Los sucesos estivales de mayor calado en la provincia fueron la muerte del pintor Joaquín Sorolla el 10 de agosto y las protestas por la guerra de África, donde destacó el incidente de un joven recluta que disparó al aire en plena Estación del Norte, animando a sus compañeros a la rebelión (Tusell y García Queipo de Llano, 2001, 399).

La crisis de la Restauración era algo palpable incluso para la prensa valenciana más conservadora. Frente a la atonía general de la clase política valenciana Las Provincias reflejaba, en julio de 1923, el deseo de buena parte de la sociedad valenciana de que ocurra algo gordo ${ }^{5}$. El entonces concejal republicano Vicente Marco Miranda afirmaba que el golpe debía darse en fechas posteriores al 13 de septiembre. Fue el temor a ser descubierto por el Gobierno el que precipitó los acontecimientos. En Barcelona el general Ochoa fue el encargado de iniciar la sublevación junto a sus subordinados, los coroneles Vergara y Alcántara.

El golpe legitimó el recurso a la violencia y a las armas para llegar al poder (González Calleja, 1999, 269). Además era heredero de los espadones decimonónicos (Juliá, 1999, 68-69). La mayoría de plazas militares españolas secundaron el golpe sin más. Una de las más notables excepciones la encontramos en Valencia. En efecto el País Valenciano constituía un territorio sumamente importante debido a su proximidad a Cataluña. Sin embargo la actitud dubitativa del general Zabalza, capitán general de la región, iba a poner en peligro la empresa primorriverista (Vázquez de Prada, 2001, 60-61). La adhesión de Zabalza era previsible para el militar jerezano, debido a que este último había servido

\footnotetext{
${ }^{5}$ Las Provincias, 10-7-1923.
} 
como capitán general de la III Región Militar a la que pertenece Valencia (Tusell, 1987, 175-176). Durante la noche del 12 al 13 de septiembre se ocuparon los principales edificios públicos de Valencia ${ }^{6}$.

La discrepancia de Zabalza la noche de la asonada fue más táctica que política. De hecho no llevó a cabo acción militar alguna contra plazas militares que sí habían secundado el golpe en contra del gobierno vigente. La documentación existente en el Archivo Histórico Nacional nos lleva a pensar en la posibilidad de que Zabalza estuviera ganando tiempo para decantarse por uno u otro bando en función del éxito final. Primo de Rivera no podía esperar más y unas horas más tarde escribía a Zabalza un telegrama advirtiéndole de las consecuencias de sus acciones. Tanto Primo de Rivera como Sanjurjo, gobernador militar de Zaragoza, tomaron la decisión de enviar a García Trejo, gobernador militar de Castellón, para que tomara medidas contra la ciudad de Valencia. Éste envió al teniente coronel Joaquín Tirado a Valencia la tarde del 14 de septiembre. Llegado a la ciudad se puso en contacto con el general Balbino Gil Dolz, gobernador militar de Valencia, y, tras convocar ambos a todos los coroneles de la plaza militar, arrebataron el mando militar a Zabalza (Marco Miranda, 1975, 23).

El memorándum de Gil Dolz con fecha del 15 de septiembre, y dirigido a Miguel Primo de Rivera, no dejaba lugar a dudas, resaltando:

[...] lo que moralmente habré sufrido en la titánica lucha sostenida, casi sin interrupción, en el plazo antedicho con el general Zabalza, para lograr llevar a su ánimo el convencimiento de que debía adherirse sin reservas, al noble acto que con la gallardía innata en Vd. había realizado. Mis leales, honrados y desinteresados propósitos, se estrellaron una y mil veces ante la obstinada resistencia y actitud de dicho Sr.

[...] de nadar entre dos aguas, capear el temporal hasta ver venir, de esperar, de aplazar la cosa hasta tener noticias concretas de Madrid, dando pruebas de una lamentabilísima indecisión que pudo ocasionar graves y punibles actos de indisciplina que trataba yo de evitar a todo trance, ya que conocía la resuelta actitud de la guarnición ${ }^{7}$.

Tras apartar a Zabalza el propio Gil Dolz se convertía en capitán general accidental ${ }^{8}$. La indignación de Gil Dolz le había llevado incluso a presionar a

${ }^{6}$ El propio Foreign Office había advertido de que la situación era favorable al golpe en toda España. The National Archives, sección Foreing Office, W 7238.

7 Archivo Histórico Nacional, sección Gobierno de Primo de Rivera, leg. 465.

8 Antes de presentar su dimisión Zabalza envió un telegrama al nuevo gobierno donde exponía su aislamiento respecto de la oficialidad, siendo la dimisión la única salida posible. 
Zabalza en su propio despacho mediante la presencia de generales y coroneles de la Capitanía General, con la intención de que proclamase el estado de guerra en la región y pudiesen cumplirse las directrices de Primo de Rivera. Los coroneles de la región militar ya sólo obedecían a Gil Dolz, por lo que un hipotético cambio en la postura del general Zabalza ya no hubiera surtido efecto. Zabalza era ya un militar defenestrado por los oficiales golpistas y la proclamación del estado de guerra era solamente cuestión de tiempo.

El gobierno militar pasó a estar regido por Gómez Alberti. Al tomar posesión de su cargo ese mismo día 14 de septiembre, el nuevo capitán general Gil Dolz regresó a Capitanía y efectuó la tan ansiada declaración del estado de guerra en toda la Región Militar'. Acto seguido dirigió a la Casa Real un telegrama donde reiteraba a Alfonso XIII su adhesión incondicional. Por la tarde fue leído el bando del general Gil Dolz por el coronel Peoly en los siguientes términos:

Que recogiendo las ansias del país de apartar de la gobernación del Estado a los profesionales de la política, el Ejército que represento en esta región, ha acordado asumir provisionalmente el mando de las facultades inherentes al gobierno en esta región ${ }^{10}$.

En resumen, la llegada de la dictadura en el País Valenciano se produjo, al igual que a nivel español, de forma incruenta y con un cierto entusiasmo por parte de la opinión pública. El incidente de Zabalza ha de verse como una acción oportunista más que como una disensión dentro del estamento militar. El golpe militar ha de considerarse como el resultado de un proceso que arrancó décadas atrás, y que culminaría en el fin del parlamentarismo vigente en España desde 1874. En el caso español los acontecimientos se precipitaron desde el desastre de 1898 y se agudizaron por las transformaciones económicas ocurridas por la Gran Guerra. La inexistencia de golpes militares desde 1874, cuando Martínez Campos proclamó rey en Sagunto a Alfonso XII, no fue óbice para que el Ejército se sintiera con fuerza para ejercer de árbitro en la política española. Tras unas décadas iniciales de mayor estabilidad dentro de los sucesivos gobiernos posteriores a 1918 se empezó a vislumbrar una solución mediante la toma del poder ejecutivo por parte de militares reaccionarios.

9 Balbino Gil Dolz del Castellar y Peyró había nacido en Valencia el 31 de Marzo de 1858, y era hijo de Vicente Gil Dolz, conde de Albalat. Ingresó en el Ejército el 22 de Junio de 1874 como Cadete de Infantería y ascendió al grado de General de Brigada el 16 de Mayo de 1914. El 19 de Abril de 1920 era General de División. Archivo General Militar de Segovia, sección expedientes militares, leg. J-204.

10 Las Provincias, 15-9-1923. 


\section{LA DESAPARICIÓN DEL GOBIERNO CIVIL}

La progresiva desaparición de las instituciones existentes ocupó la primera fase de la dictadura, desde el momento del golpe hasta enero de 1924. El día 15 de septiembre se produjo una suerte de coordinación interprovincial entre los gobernadores militares que componían la Tercera Región Militar. En un comunicado publicado en la prensa escrita, el capitán general especificaba que los gobernadores militares de las provincias de Alicante, Albacete, Almería y Murcia [...] debían hacerse cargo del mando civil de su provincia, destituyendo a los gobernadores civiles y declarando el estado de guerra ${ }^{11}$.

El hecho de que los gobiernos civiles fueran sustituidos por los militares se debía a la desconfianza de los militares hacia la vieja política llevada a cabo hasta entonces. La mentalidad política del general Primo de Rivera y del resto de miembros del Directorio Militar adolecía de una nula confianza en los elementos civiles de la sociedad española a la hora de salir del complejo panorama en el que se encontraba el estado. Todo ello iba acompañado de la respectiva declaración de guerra en cada provincia, que seguía la situación por la que atravesaba Valencia tras la famosa proclama del general Balbino Gil Dolz.

La organización piramidal del poder ejercido por Primo de Rivera sería más eficaz en la medida en que se eliminaran interferencias entre las ramas civil y militar a la hora de cumplir órdenes. La represión, al menos, sólo se dirigió hacia políticos influyentes y siempre bajo forma de exilios o postración civil. El vilipendiado García Prieto, presidente del Consejo de Ministros durante 1922 y 1923, se encontró con la nueva situación política en España; la enemistad de Primo de Rivera hacia él se hizo patente desde el principio del nuevo régimen. El consulado británico en San Sebastián ya empezaba a citar nombres de responsables el 17 de septiembre:

Yesterday morning, however, a notice was posted at the offices of the 'Pueblo Vasco' the principal paper here saying that general Primo de Rivera, marqués de Estella, Captain General of Catalonia had (as reported in my unnumbered telegram of the $13^{\text {th }}$ dispatched from Hendaya) on his own initiative declared state of siege (Estado de Guerra) throughout the Province and issued a Manifesto (translation of which I enclose) calling on the King to dismiss the present Government and declaring his intention to prosecute Don Santiago Alba the Minister for Foreign Affairs, and the Prime Minister, Marqués de Alhucemas for supporting this depraved and cynical Minister ${ }^{12}$.

\footnotetext{
11 Las Provincias, 16-9-1923.

12 The National Archives, sección Foreign Office, W 7311.
} 
La opción de supeditar, al menos temporalmente, el brazo civil al militar era consecuencia lógica de la mentalidad de unos militares formados en unos valores puramente autoritarios, donde el Ejército se presentaba como el auténtico salvador de España desde tiempos pretéritos. Esto supuso un empeoramiento de las relaciones civiles-militares (Navajas Zubeldia, 1989, 165) ${ }^{13}$. El Ejército, según la perspectiva más conservadora y autoritaria, sería la institución que podría restablecer la regeneración moral dentro de España y alejaría la posibilidad de cualquier ataque que se realizaría en consonancia con la ola roja y la invasión de aquella marea de destrucción de los principios de la civilización occidental (Pemartín, 1929, 70).

Los nuevos gobernadores tendrían la misión de ejercer un poder coactivo donde la libertad de prensa estaba seriamente restringida, en un intento de adoctrinar a las masas con unos medios de comunicación que cada vez cobraban más importancia. El cese del gobierno civil, sustentado en la Real Orden del 15 de septiembre de 1923, disponía que en los casos en que el gobernador militar no residiera en la capital de la provincia se haría cargo del gobierno civil el jefe militar más caracterizado, con residencia permanente en ellas ${ }^{14}$.

En general toda la prensa coincidía en afirmar, durante los dos días siguientes al golpe, que tanto el Ejército como los mandos de la Guardia Civil estaban de parte de los militares sublevados y no tenían intención de defender ni por un instante al régimen depuesto. Las órdenes desde Madrid no cesaban y el mismo día se informaba a Gil Dolz que su brevísima situación interina en la capitanía general tocaba a su fin tras el nombramiento del teniente general Bernardo Álvarez del Manzano para dicho puesto ${ }^{15}$. Además, para circular fuera de la provincia en automóvil o motocicleta se necesitaría un permiso facilitado por el Gobierno Civil ${ }^{16}$.

La maquinaria burocrática de la dictadura en la provincia de Valencia empezaba a ponerse en funcionamiento. En adelante, el gobernador militar tendría amplios poderes para nombrar o suspender en sus tareas a funcionarios de organismos públicos o controlar el nacimiento del partido único del régimen, la Unión Patriótica.

Las muestras de agradecimiento y alegría con que fue acogido el golpe en Valencia hacían presagiar una fiebre regeneradora sin límites. Como ha descrito Javier Tusell, en España se produjo el nacimiento de un mesianismo regeneracionista y anticaciquil; tras largas décadas de gobiernos débiles una desbocada ansia regeneracionista parecía haberse apoderado de los españoles (Tusell, 1977, 45).

13 Para profundizar más en el funcionamiento del Ejército en estos años, del mismo autor, Navajas Zubeldia, C. (1992): Ejército, estado y sociedad en España (1923-1930), Logroño, Instituto de Estudios Riojanos, 314 p.

14 Gaceta de Madrid, 17-9-1923.

15 Idem.

${ }^{16}$ El Pueblo, 16-9-1923. El Pueblo, además, informaba que los gobernadores militares de cada provincia ya habían proclamado el estado de guerra en cada provincia. 


\section{LOS CAPITANES GENERALES}

Los capitanes generales habían desempeñado desde el siglo XIX las funciones de mando superior de las regiones militares. Este cargo era temporal y respondía a un mandato sancionado por el propio monarca. No obstante, podía ser cesado o no renovado en el mismo. En 1898 la Capitanía General de Valencia o III Región Militar quedó formada por las siguientes seis provincias: Valencia, Alicante, Castellón, Murcia, Albacete y Cuenca. Los nombramientos de los capitanes generales no respondían a un criterio claro. Además, tenemos el inconveniente de que muchos de estos cargos militares estaban muy poco tiempo en ejercicio debido a otros nombramientos propios del Ejército.

Cuadro 1. Lista de capitanes generales de la III Región Militar (1921-1930) ${ }^{17}$

\begin{tabular}{|l|l|}
\hline \multicolumn{1}{|c|}{ Periodo } & \multicolumn{1}{|c|}{ Nombre } \\
\hline $\begin{array}{l}\text { 9 de junio de } 1921 \text { hasta el } 17 \text { de enero de } \\
1922\end{array}$ & Luis Aizpuru Mondéjar \\
\hline $\begin{array}{l}\text { Del } 17 \text { de enero de } 1922 \text { hasta el } 17 \text { de } \\
\text { septiembre de } 1923\end{array}$ & José Zabalza e Iturriria \\
\hline $\begin{array}{l}\text { Del } 17 \text { de septiembre de } 1923 \text { al } 7 \text { de } \\
\text { diciembre de } 1923\end{array}$ & Bernardo Álvarez del Manzano y Menéndez Valdés \\
\hline $\begin{array}{l}\text { Del } 7 \text { de diciembre de } 1923 \text { a } 31 \text { de } \\
\text { octubre de } 1927\end{array}$ & Ventura Fontán \\
\hline $\begin{array}{l}\text { Del } 31 \text { de octubre de } 1927 \text { hasta el } 16 \text { de } \\
\text { abril de 1928 }\end{array}$ & Balbino Gil Dolz del Castellar \\
\hline $\begin{array}{l}\text { Del } 16 \text { de abril de } 1928 \text { hasta el } 30 \text { de } \\
\text { abril de } 1929\end{array}$ & Alberto Castro Girona \\
\hline $\begin{array}{l}\text { Del } 30 \text { de abril de } 1929 \text { hasta el } 28 \text { de } \\
\text { enero de } 1930\end{array}$ & Eladio Pin Ruano \\
\hline
\end{tabular}

${ }^{17}$ Almanaque Las Provincias, años 1923 a 1931. 
Es necesaria una prosopografía de estos cargos militares debido a la importancia que tuvieron sus decisiones en detrimento de otros estratos sociales (Del Rey Reguillo y Moreno Luzón, 1996, 178). Tras poco más de medio año en el cargo, Luis Aizpuru, sucesor del propio Miguel Primo de Rivera como capitán general de Valencia, pasaba a ser jefe del Estado Mayor Central en enero de $1922^{18}$. Era un ascenso en toda regla y este le llegó en los últimos compases del régimen restauracionista. Sin embargo la dictadura de Primo de Rivera aún le iba a conceder un último premio: el nombramiento de alto comisario de España en Marruecos ${ }^{19}$. A Aizpuru le sucedió en la Capitanía General, durante un breve periodo, José Zabalza, que no llegó a durar once meses como capitán general. Además, como ya hemos señalado, Zabalza fue sustituido de forma interina por Balbino Gil Dolz de Castellar mientras se investigaba su ambigua actuación durante el golpe de estado ${ }^{20}$. A Gil Dolz del Castellar, interino, le sucedió de forma brevísima Bernardo Álvarez del Manzano, procedente del arma de Infantería. Nacido el 15 de enero de 1859, Álvarez del Manzano había sido comandante general de Ceuta, en cuya situación fue ascendido a teniente general por méritos de guerra. Está en posesión de la gran cruz del Mérito Militar, designada para premiar servicios especiales; la gran cruz de San Hermenegildo y otras varias ${ }^{21}$.

Ventura Fontán, su sucesor, iba a ser el capitán general de Valencia con mayor permanencia en el cargo durante el régimen. Llegado en diciembre de 1923, se perfilaba como el definitivo hombre de confianza de Primo de Rivera en esta capitanía. Sin embargo no lo acabó siendo, ya que ocupó el cargo hasta el 31 de octubre de 1927, pasando entonces a la Dirección de Carabineros. Todo un logro de permanencia en lo que había sido el continuo baile de nombres, demostrando la poca paciencia que el régimen tenía con los cargos militares. Balbino Gil Dolz del Castellar volvió al cargo tras Fontán, aunque en realidad era un homenaje que le rendía el gobierno antes de su retirada en abril de 1928. Gil Dolz, valenciano, había estado destinado como capitán general de Valladolid y fue un fiel aliado de Primo de Rivera en Valencia en el golpe de 1923. Esta recompensa no impidió que fuera relevado por haber cumplido este [Gil Dolz] la edad reglamentaria y corresponderle ingresar en la reserva ${ }^{22}$.

Los últimos capitanes generales de Valencia durante la dictadura fueron Alberto Castro Girona y Eladio Pin Ruano. El primero, que apenas ocupó el

\footnotetext{
18 Gaceta de Madrid, 16-9-1923.

19 Idem.

20 Almanaque Las Provincias, año 1923.

21 Las Provincias, 16-9-1923.

${ }^{22}$ Almanaque Las Provincias, año 1928.
} 
cargo un año, llegó a Valencia con el cartel de ser uno de los generales más jóvenes y prestigiosos de nuestro ejército ${ }^{23}$. El segundo llegó en abril de 1929. Para entonces, la dictadura ya estaba moribunda y sería sustituido en el cargo a finales de enero e 1930, precisamente el mismo mes en el que Primo de Rivera abandonó el poder ${ }^{24}$.

\section{LOS GOBERNADORES MILITARES}

El Gobierno Militar era una de las bases del poder de Miguel Primo de Rivera. El nombramiento de estos altos cargos de Defensa se llevaba a cabo con su estricto consentimiento y suponían un refuerzo del gobierno central en provincias, al mismo tiempo que podían reaccionar de forma rápida a cualquier desorden cuando el Gobierno lo requiriera. De hecho, tras el golpe de estado, estos altos funcionarios recibieron una recompensa en forma de aumento de sus atribuciones mediante la Real Orden del 15 de septiembre antes citada.

La provincia de Valencia no fue una excepción y Mariano de la Revilla unificó ambas gobernaciones en virtud de dicha Real Orden. De la Revilla, además, tuvo que asumir la constitución de la nueva Diputación provincial en enero de 1924. Como aspecto polémico, deben señalarse los conflictos con las personas de etnia gitana que mantuvo a causa de los altercados que las mismas tenían con la Guardia Civil ${ }^{25}$.

Fue sustituido, a partir del 9 de febrero de 1924, por Juan García Trejo, anterior gobernador militar de Castellón. García Trejo era general de división y presentaba una larga hoja de servicios como militar $^{26}$. Su permanencia en el cargo ocupó buena parte de la dictadura, ya que se mantuvo en el mismo hasta el día de su fallecimiento, el 18 de noviembre de 1928. Precisamente se le había concedido días atrás la Capitanía General de Zaragoza para un traslado inminente. Como apunte interesante cabe señalar que su hermana Catalina también ostentaba un cargo importante en la región: una Tenencia de Alcaldía en el Ayuntamiento de Alicante. Más allá de estos datos es difícil valorar la gestión de Garcia Trejo. La documentación encontrada sobre él es muy reducida: apenas actos

23 Idem.

24 Almanaque Las Provincias, año 1929.

${ }_{25}$ El Pueblo, 20-1-1924. Igualmente, en una demostración de torpeza, un Guardia Civil disparó a un ciudadano noruego al confundirlo con un sindicalista. El disparo le causó la muerte y fue prueba del excesivo celo con el que las autoridades deseaban reinstaurar el orden.

26 Almanaque Las Provincias, año 1925. 
protocolarios o la intervención para poder acompañar a una comisión valenciana, formada por exportadores de fruta, para gestionar asuntos importantes que les afecten ${ }^{27}$. También debemos de destacar la inauguración en su mandato de la línea telefónica directa entre Valencia y Madrid, así como de la primera estación de radiografía en Valencia, situada en el Hotel Reina Victoria.

\section{LOS GOBERNADORES CIVILES}

El Gobierno Civil era una institución que se había consolidado en la segunda mitad del siglo XIX. En principio obedecían a una cadena de mando que desde el gobierno central trasladaba a cada provincia las directrices y órdenes a seguir. La Ley de Presupuestos del 21 de julio de 1876 y la Ley Provincial del 29 de agosto de 1882 regulaban las condiciones para ser nombrado para este puesto. Básicamente se establecían dos grandes categorías: la de aquellos políticos que ya habían ocupado cargos como presidencias de Diputación, alcaldías o escaños en las Cortes, y la de los que tenían determinadas categorías profesionales, tales como militares o funcionarios al servicio de la Administración Civil del Estado. Estos nombramientos de los gobernadores civiles se llevaban a cabo mediante Real Decreto (Gómez-Navarro, 1991, 179). La suspensión de todos los gobernadores civiles se prolongó unos meses, hasta el 5 de abril de 1924, fecha en que comenzaron a ser restituidos:

Los seis meses transcurridos desde que fueron encomendados los Gobiernos Civiles a los titulares de los militares, han puesto de manifiesto la importante labor por éstos realizada, y la conveniencia de dejarla en unos casos encomendada a las mismas personas, aunque por cambio de situación militar deban ser sustituidas en sus destinos de plantilla, y en otros, ir nombrando nuevos titulares que, con carácter definitivo y civil, desempeñen las funciones propias de aquellos cargos. Para dar realidad a este criterio, S.M. el Rey a propuesta del Presidente del Directorio Militar, y de acuerdo con éste, ha tenido a bien disponer quede modificado el art. $2^{\circ}$ de la Real Orden circular de la Presidencia del Directorio Militar de 15 de Septiembre de 1923, en el sentido de que puedan hacerse nombramientos de Gobernadores Civiles en aquellas provincias en que, a juicio del Directorio, convenga sean sustituidos los militares que actualmente vienen ejerciendo tales funciones (Gómez-Navarro, 1991, 180-181).

27 Archivo General de la Administración, sección Gobernación, 44/143, leg. 6. 
Las razones por las que se operaba este cambio debemos encontrarlas en el rechazo castrense a participar en la gestión de asuntos civiles. Los propios integrantes del Directorio Militar se oponían a que los militares de alta graduación, y con ellos el Ejército, sufrieran el desgaste propio de gestionar una provincia y ser la cara visible del régimen en la misma (Paredes Alonso, 2004, 487). Además, la pugna dentro del estamento militar para conseguir mejores destinos tampoco contribuía a seguir con el predominio castrense en este escalafón político.

Para perfilar la nueva situación, el 9 de abril de 1924 se publicaba un Real Decreto donde se eliminaba cualquier requisito para poder aspirar al cargo. De este modo, el control del gobierno central sobre estos nombramientos era total y absoluto. El Directorio Militar debió entender que esta situación no era la correcta, ya que menos de un año después, el 20 de marzo de 1925, se aprobaba el Estatuto Provincial donde se fijaban de forma definitiva las funciones y condiciones de los gobernadores civiles ${ }^{28}$. Este nuevo reglamento igualmente establecía las condiciones necesarias para poder optar a gobernador civil. Aparecían tres grupos diferenciados por este reglamento. En primer lugar los que habían ocupado cargos políticos de nombramiento, tales como ministros, directores generales o electos, como diputados, senadores o alcaldes de ciudades de más de 30.000 habitantes. En segundo lugar podían aspirar a ser gobernadores civiles aquellos funcionarios de la administración estatal que hubieran aprobado una plaza por oposición, como notarios, registradores, diplomáticos, catedráticos, etc. El tercer grupo lo formaban los jefes del Ejército y los que hubieran pertenecido a la carrera judicial ${ }^{29}$. No obstante aunque el abanico de candidatos a esta magistratura quedaba considerablemente ampliado respecto a años anteriores, en la provincia de Valencia, como veremos a continuación, la mayoría de gobernadores civiles fueron militares.

A la hora de estudiar los expedientes de los gobernadores civiles provinciales cabe decir que, de la lista antes expuesta, todos los gobernadores hasta 1923 tienen su expediente en el Archivo General de la Administración (AGA). Para estudiar los gobernadores nombrados por Primo de Rivera hay que recurrir a la Gaceta de Madrid o a la prensa de la época.

De los titulares del Gobierno Civil previos al golpe de 1923 debemos destacar su carácter efímero. Es importante destacar este hecho para comprobar hasta qué punto los últimos gobiernos previos al golpe improvisaban sus nombramientos. La década de 1920 se inicia con Rafael Durán Martín como go-

${ }^{28}$ Gaceta de Madrid, 21-3-1925.

${ }^{29}$ Idem. 
Cuadro 2. Lista de gobernadores civiles de la provincia de Valencia (1920-1931) ${ }^{30}$

\begin{tabular}{|c|c|}
\hline Fecha & Nombre del gobernador civil \\
\hline $17-4-1919$ a $17-5-1920$ & Rafael Durán Martín \\
\hline $17-5-1920$ a $14-10-1920$ & José de Sousa y del Real \\
\hline $14-10-1920$ a $25-2-1921$ & Salvador Muñoz Pérez \\
\hline 26-2-1921 a $11-5-1921$ & Rafael Ripoll Cabrera \\
\hline $11-5-1921$ a $6-9-1921$ & Julio Blasco Perales \\
\hline 6-9-1921 a $15-4-1922$ & José Calvo Sotelo \\
\hline $15-4-1922$ a $12-12-1922$ & Rafael García Ormaechea y Mendoza \\
\hline $12-12-1922$ a $19-9-1923$ & Francisco Javier Cabello y Lapiedra \\
\hline $14-12-1925$ a $27-12-1927$ & José Álvarez Rodríguez \\
\hline $27-12-1927$ a $24-1-1929$ & Cristino Bermúdez de Castro \\
\hline $24-1-1929$ a 7-2-1930 & Heraclio Hernández Malillos \\
\hline $7-2-1930$ a $15-2-1930$ & Luis Suárez y Alonso-Fraga \\
\hline $15-2-1930$ a $15-1-1931$ & Luis Amado y Reygondaud de Villebardet \\
\hline $16-1-1931$ a $1-3-1931$ & Lorenzo del Villar Losada \\
\hline 2-3-1931 a $14-4-1931$ & Buenaventura Sánchez Cañete \\
\hline $18-4-1931$ a 4-6-1931 & José Centeno \\
\hline $5-6-1931$ a $2-7-1931$ & Federico Fernández Castillejo \\
\hline
\end{tabular}

bernador civil de la provincia de Valencia. En su expediente apenas consta su paso posterior por el Gobierno Civil de Sevilla tras cesar en Valencia ${ }^{31}$. Su sucesor, José de Sousa y del Real, general de artillería, tomó posesión efectiva

${ }^{30}$ Archivo General de la Administración, sección Gobernación y Gaceta de Madrid.

31 Archivo General de la Administración, sección Gobernación, caja 44, leg. 18.969. 
del cargo el día 17 de mayo de 1920. Como nota anecdótica, cabe señalar que, los dos días que se demoró su traslado hasta la capital de provincia, el nombramiento de gobernador civil interino recayó en Valentín Escribano, presidente de la Audiencia provincial ${ }^{32}$.

Apenas medio año ocupó su cargo Sousa. Para el mes de octubre de 1920, Salvador Muñoz Pérez, que había sido alcalde de Córdoba en tres períodos diferentes lo sustituyó ${ }^{33}$. Fue nombrado gobernador civil de Valencia tras pasar por el mismo cargo en la provincia de Castellón ${ }^{34}$. De su sustituto, Rafael Ripoll Cabrera, podemos destacar su brevedad en el cargo, que sólo ocupó durante tres meses ${ }^{35}$.

A Francisco Javier Cabello y Lapiedra, abogado del estado, le sorprendió el golpe militar en el Gobierno Civil. Este hecho supuso su pronta destitución, efectiva el 19 de septiembre de $1923^{36}$. Con anterioridad había sido gobernador civil de la provincia de Murcia $^{37}$. Su actitud ante el golpe militar no fue de oposición radical, sino que presentó la dimisión con prudencia y siendo fiel al gobierno dimisionario.

La documentación encontrada en el Archivo General de la Administración sobre Cabello Lapiedra es importante debido a que el 18 de septiembre de 1923, un día antes de su cese oficial en la Gaceta de Madrid, es nombrado miembro de la sección especial de excedentes del escalafón de la Presidencia del Consejo de Ministros. No consta que tuviera sueldo a cargo del estado, pero sin duda la importancia de estar relacionado con ministros y altos cargos debía ser muy influyente. Los méritos alegados por el exgobernador civil consistían en tener:

[...] más de 28 años de servicios al Estado, [haber desempeñado] el cargo de Gobernador Civil en tres etapas consecutivas, contando hoy con más de dos años de servicio y menos de diez en el expresado cargo de Gobernador, y que la condición de ser o estar comprometido en la categoría de Jefe de Administración de primera clase, excedente sin sueldo, implica el derecho a ser incluido en los escalafones de la Presidencia ${ }^{38}$.

32 La Correspondencia de Valencia, 15-5-1920.

${ }_{33}$ Gaceta de Madrid, 15-1-1920.

${ }^{34}$ Archivo General de la Administración, sección Gobernación, caja 44, leg. 19.028.

35 Archivo General de la Administración, sección Gobernación, caja 44, leg. 19.052.

36 Archivo General de la Administración, sección Gobernación, caja 44, leg. 18.949.

37 Gaceta de Madrid, 23-4-1919.

38 Archivo General de la Administración, sección Presidencia, caja 51/3.473, leg. 137. 
En ocasiones debía hacer frente a alcaldes y equipos de gobierno como el del municipio de Domeño, en la comarca de los Serranos, al que tuvo que cesar al completo en relación con el cumplimiento de determinados servicios ${ }^{39}$. Tras el cese de Cabello Lapiedra entramos en el paréntesis de suspensión del Gobierno Civil. José Álvarez Rodríguez, que fue el primer Gobernador Civil tras el paréntesis, se convertía en el primer civil en ocupar este cargo ${ }^{40}$. Lo más novedoso es que provenía de la carrera judicial. En la Gaceta de Madrid encontramos abundante información acerca de sus nombramientos como jurista, ya sea como teniente fiscal de la Audiencia territorial de Albacete, magistrado de la Audiencia provincial de Murcia, magistrado de la Audiencia provincial de Alicante, presidente de la Audiencia de Huesca o juez de primera instancia del distrito del Centro de Madrid.

Su llegada a Valencia despertó la atención de todas las autoridades, a cuyo frente figuraban los señores arzobispo y capitán general; nutridas representaciones de la Diputación y Ayuntamiento; a casi todos los funcionarios de la administración de justicia, con el presidente de la Audiencia ${ }^{41}$. El problema del abastecimiento de alimentos debía ser acuciante en la provincia, ya que sus primeras declaraciones a la prensa iban en el sentido de mejorar este servicio:

Hay cuestiones, como por ejemplo, la de abastos y subsistencias, en las que la gestión de los gobernadores llega antes al público, y en ellas he de ocuparme ya, puesto que he llamado a los inspectores de abastos para reiterarles ciertas instrucciones y darles otras nuevas. A esta labor de velar porque las subsistencias no encarezcan y por la pureza de sus cualidades, la exactitud en el precio y la conveniente abundancia de ellas, he de prestar una atención directa, personal, todo lo perseverante que me sea posible ${ }^{42}$.

Siguiendo con la política de apaciguamiento del sector agrario encontramos la constitución del Comité provincial algodonero de Valencia. Este comité estaba enmarcado dentro de las directrices económicas proteccionistas del Directorio Civil, en este caso regulado por la Real Orden de 23 de diciembre de 1925. La zona interior de la provincia también contó con la intervención del gobierno. El 1 de mayo de 1926 se enviaba un telegrama desde el Gobierno

39 Archivo General de la Administración, sección Gobernación, caja 44/306, leg. 11.

${ }^{40}$ Las Provincias, 11-12-1925. Mientras la Gaceta de Madrid certifica que el nombramiento oficial es del 14 de diciembre, Las Provincias afirma que el relevo se decidió en el Consejo de Ministros celebrado el 9 de diciembre.

41 Las Provincias, 20-12-1925.

42 Las Provincias, 22-12-1925. 
Civil a Madrid donde se dejaba constancia del agradecimiento de la Unión Vitícola de Levante, de la Cámara Oficial Agrícola y representaciones de los agricultores de Utiel, Villena o Pedralba para manifestar reconocimiento por [la] publicación [del] decreto que resuelve [la] crisis vinícola ${ }^{43}$.

Los homenajes al general Primo de Rivera en la provincia siguieron en esta fase del Gobierno Civil, consistentes por ejemplo en la colocación de la primera piedra en el monumento que en Gandía se tributó al presidente del Directorio ${ }^{44}$. En Requena, se dio inicio a una serie de conferencias propagandísticas, el 18 de marzo de 1926, con un homenaje político al dictador en el teatro Romea con la presencia del alcalde de la localidad y el capellán Sr. Madrid, contando esta con gran concurrencia (e) inusitado entusiasmo. Este acto tendría continuidad en la vecina localidad de Utiel el 23 de marzo ${ }^{45}$. En otras ocasiones también se dedicaba un homenaje a personalidades relevantes desde el propio Gobierno Civil, como el caso de José Serrano, creador del himno regional valenciano, al que se le tributó un homenaje en vida en agosto de 1926. Al acto del inicio de la construcción de la casa para el maestro valenciano, sufragado por el Ayuntamiento de Valencia, acudió el propio Álvarez Rodríguez. El 27 de diciembre de 1927 Álvarez Rodríguez fue sustituido por Cristino Bermúdez de Castro $^{46}$.

Nacido en 1866, Bermúdez ya había ejercido como gobernador civil de Alicante (Pérez Ortiz, 1990, 48-49). La carrera de este militar estaba ligada al arma de infantería, siendo nombrado para el cargo por sus condiciones de gobernante firme y carácter independiente, [teniendo] aptitudes especiales para la resolución de los asuntos administrativos, siempre dentro del más estricto espíritu de justicia ${ }^{47}$. Pronto tuvo ocasión de encontrarse con un incidente que gestionar, debido a un motín en la cárcel que se había habilitado en el antiguo monasterio de San Miguel de los Reyes. Según un telegrama enviado el 22 de marzo de 1928 por el propio Bermúdez de Castro al ministerio de la Gobernación, los hechos comenzaron por la imposición de un castigo a un penado que presentaba un comportamiento inadecuado, originándose:

43 Archivo Histórico Nacional, sección Gobierno Primo de Rivera, leg. 369/2.

${ }^{44}$ Idem, la carta en la que el alcalde de Gandía solicita a Álvarez su presencia en el acto publicitario está fechada el 20 de enero de 1926.

${ }^{45}$ Idem.

46 Gaceta de Madrid, 28-12-1927. Entre ambos ejerció como gobernador civil interino el señor Peiró.

47 Las Provincias, 29-2-1927. 
[...] [el] día 20 [de marzo] un plante en el Penal de San Miguel de los Reyes, que pudo ser reducido merced a la intervención del personal del establecimiento, aún cuando la población penal continuó ayer produciendo manifestaciones de desagrado contra el Administrador del mismo de quien, al parecer, están descontentos. Se han adoptado medidas disciplinarias y redoblado la vigilancia por la fuerza pública, interviniendo en el asunto las autoridades judiciales. Hoy hasta ahora no hay novedad en el establecimiento, no habiéndose permitido salgan de sus celdas penados hasta que depongan su actitud ${ }^{48}$.

En los años veinte la falta de infraestructuras adecuadas y de comunicaciones tampoco facilitaba la tarea de los gobernadores. Ya en su periodo la provincia de Alicante había padecido estas deficiencias en la celebración del Plebiscito nacional, al no poder comunicarse adecuadamente con los delegados gubernativos o alcaldes de la provincia.

De sus diferencias con su antecesor, Álvarez, no nos ha dejado constancia la prensa de la época. Sin embargo, al investigar en el Archivo Histórico Nacional, encontramos un escrito dirigido por Bermúdez de Castro a Primo de Rivera donde citaba de una forma un tanto despectiva a Álvarez. Este escrito estaba motivado por un problema en el Ayuntamiento de Xàtiva. El secretario de dicho consistorio, Larrea, había tenido diferencias con los concejales usando amenazas y coacciones para imponer su voluntad. En dicho informe se realza la influencia que Larrea gozaba durante la etapa de Álvarez:

Te mando un extracto del expediente que instruye el Delegado gubernativo al Secretario del Ayuntamiento de Játiva, Señor Larrea. La situación es insostenible. Él y un hermano suyo soldado de cuota con garrotes y pistolas y uno o dos de los matones que tiene a su servicio, se han impuesto al pueblo, contando con las influencias que tiene, y que era efectiva en época de mi antecesor Sr. Álvarez. Los que han de declarar ante el Concejal instructor, lo hacen después de haber sido amenazados y ya el Ayuntamiento ha expulsado a más de un empleado con varios pretextos y nadie se atreve a ir contra dicho Secretario. Todo lo arregla a su antojo y un Concejal me confiesa que no pueden con él, pues ni los empleados le hacen caso. Al Jefe de la Unión Patriótica, Sr. de Diego lo ha aislado y ha prometido que el [que] vaya a verle, o le hable en el Casino o calle se acordará de él.

[...]

Es un mal caballero y miente, miente. En Játiva se ha erigido en el terror del Ayuntamiento ${ }^{49}$.

48 Archivo Histórico Nacional, sección Gobierno Primo de Rivera, leg. 369/2.

49 Idem. Al analizar los discursos en la toma de posesión de Bermúdez de Castro no se aprecia ninguna diferencia significativa entre ambos, incluso Álvarez agradeció a Primo 
De la documentación existente sobre este caso no consta más que este expediente que el gobernador civil mandó al Ministerio de la Gobernación. Bermúdez de Castro sospechaba que el comportamiento de Larrea se debía:

[...] a una conjura tramada por enemigos del régimen para acabar con el anterior Ayuntamiento, creyendo con ello inferir gravísimo quebranto a nuestro partido. El día treinta y uno del pasado Julio recibí a las diez de la mañana la visita del Teniente Alcalde y médico de cabecera, Don José Llixiona que vino a que le diera instrucciones acerca de si debía o no ir al Ayuntamiento, ya que según sus noticias se trataba de crear un conflicto al poder constituido al que no podía nunca prestar aquiescencia y siempre su repulsa más rotunda ${ }^{50}$.

A inicios de 1929, Bermúdez de Castro fue cesado en el cargo. Las razones, al consultar la prensa, obedecían a su estado de salud:

El secretario particular [del gobernador civil] manifestó a los periodistas, por encargo del señor Bermúdez de Castro, que este señor había enviado a Madrid la dimisión de su cargo, ya que, debido a su delicado estado de salud, no puede continuar atendiendo a las obligaciones que el mismo lleva aparejadas ${ }^{51}$.

Su sustituto, Heraclio Hernández Malillos, tomó posesión del cargo el 24 de enero de 1929. De su currículum encontramos una reseña en la prensa, donde se destaca que ha sido jefe superior de Policía en Barcelona, y es coronel de la Guardia civil. Fue quien sustituyó al general Arlegui en la Jefatura de Barcelona $^{52}$. Lo más destacado de su período como gobernador lo encontramos en las protestas de los estudiantes de la Facultad de Medicina. De esas protestas dio cuenta al propio presidente del Consejo de Ministros:

El Rector de la Universidad me participa que hoy a la una se le ha presentado una comisión de estudiantes de la Facultad de Medicina para participarle que mañana trece piensan realizar un acto de protesta no entrando en clase, habiéndoles hecho el Rector las advertencias correspondientes. Por si éstas no son atendidas he dispuesto medidas necesarias para garantizar tranquilidad pública y libertad de entrar en clase ${ }^{53}$.

de Rivera el haberlo relevado en el cargo para reintegrarse a la carrera judicial que tan entusiásticamente amo, prosiguiendo mi cargo en Madrid. El Pueblo, 25-12-1927.

50 Idem.

51 Las Provincias, 25-1-1929.

52 Las Provincias, 26-1-1929.

53 Idem. El telegrama, transcrito en Las Provincias, está fechado el 12 de marzo de 1929, a las 15:35 horas. 
Ni en la prensa ni en la documentación existente en los archivos nos ha quedado constancia de que estas actuaciones adquirieran un carácter más grave. En la edición de Las Provincias del 14 de marzo ya se informaba de que las protestas de los estudiantes cesaron tras ser aconsejados por rector y catedráticos que se retirasen ${ }^{54}$. Posteriormente, en enero de 1930, se volvieron a reproducir las protestas estudiantiles, coincidiendo con los últimos días de gobierno de Primo de Rivera. El propio Hernández Malillos reconocía que los estudiantes de Derecho y Medicina se negaban a entrar en las clases ${ }^{55}$. La situación pareció calmarse con la dimisión del dictador. Durante la primera semana de febrero todas las noticias indican que las clases discurrieron con total normalidad en la Universidad de Valencia.

Si que encontramos en el Archivo Histórico Nacional un memorándum de enorme valor enviado por Hernández Malillos a Primo de Rivera. Esta extensa carta nos da gran cantidad de información, desde la situación política de los republicanos hasta la oleada de obras públicas realizadas en numerosas localidades. De la detallada carta podemos citar un interesante fragmento que trata acerca de los republicanos:

Como aquí todavía quedan sedimentos de republicanismo de los tiempos de los blasquistas, azzatistas y sorianistas y parecía tenían cierta libertad. He creído conveniente atajarla; pidieron permiso a los pocos días de llegar para celebrar una porción de actos en honor de Blasco Ibáñez, algunos de los cuales consistía en ir a los niños de las Escuelas laicas a plantar un laurel de la casa de aquel en la Malvarrosa, distribuyéndoles premios en un centro Republicano y por la noche celebrar un mitin en honor del muerto. Negué permiso para estos actos por haberme enterado de que el día del aniversario de su muerte, transitaron por las calles, poco menos que en procesión todos los republicanos.

[...]

También tuve conocimiento que el día 11 del actual se reunieron sin previa autorización, en casa de un vecino de Alcira, unos cuantos individuos de aquella población, todos ellos de ideas republicanas, [...] les he impuesto una multa de mil pesetas a cada uno de ellos, basándome en que apareciendo en el telegrama la firma de todos, se agrega "sigue las firmas" dando la sensación con ello de una adhesión de masas que en realidad no existía. Con esta sanción creo [que] irán entrando en razón ${ }^{56}$.

54 Las Provincias, 14-3-1929.

55 Las Provincias, 30-1-1930.

${ }^{56}$ Archivo Histórico Nacional, sección Gobierno de Primo de Rivera, leg. 369/2. 
Tras Hernández Malillos se produjo la llegada al gobierno civil de Luis Suárez y Alonso-Fraga. El nombramiento oficial se produjo el 7 de febrero de 1930, pero su situación era de absoluta interinidad ${ }^{57}$. La semana que estuvo en el poder provincial fue realmente intensa, como consecuencia de los acontecimientos de Sagunto, donde los obreros reclamaban un aumento del 30\% del sueldo en ese momento ${ }^{58}$. Las sucesivas reuniones del comité paritario no sirvieron para encontrar una solución satisfactoria para los obreros. Esta llegaría con el siguiente gobernador civil, sustituto del efímero Luis Suárez. Tras la caída de Primo de Rivera el propio general Berenguer, conde de Xauen, tuvo que reunirse con Alfonso XIII para comunicarle personalmente la decisión de cesar a todos los gobernadores civiles, a excepción de los de Madrid y Barcelona ${ }^{59}$.

Sorprendentemente, no consta que ninguno de los gobernadores antes mencionados perteneciera a Unión Patriótica. Este hecho contrasta con la política de nombramientos de alcaldes, donde sí era frecuente pertenecer al este partido para ser designado. Podríamos considerar a ambos colectivos, gobernadores y Unión Patriótica, como dos grupos separados, a menudo enfrentados a la hora de tomar decisiones. El propio Gómez-Navarro nos cita en su estudio clásico de la dictadura la preferencia de Primo de Rivera por los gobernadores civiles a la hora de resolver conflictos entre ambos grupos:

En la mayoría de los conflictos entre gobernadores civiles y autoridades provinciales y locales [Diputaciones, Ayuntamientos, Unión Patriótica], aquellos recibieron el apoyo de Primo de Rivera. Hasta el punto de que sometieron y reestructuraron a las referidas autoridades. Este fue el caso de Las Palmas, donde Primo autorizó al gobernador a que procediera 'con toda la calma que juzgue precisa a impulsar y orientar su reconstitución' [refiriéndose a la Unión Patriótica]. Añadiendo más adelante: 'V.E. tiene plena confianza del gobierno [...] así pues resolverá sin apelación asuntos pendientes'. Un caso similar se produjo en Orense, y Primo contestó al jefe provincial de Unión Patriótica que no admitía ninguna presión del partido para que relevara al Gobernador Civil. De hecho, el mandato de éste se prolongó dos años más (Gómez-Navarro, 1991, 198).

El hecho de que Primo de Rivera fuera más sensible a los intereses de los gobernadores puede deberse a motivos de control del orden público o de simple

57 Las Provincias, 8-2-1930.

${ }_{58}$ El País, 16-2-1930.

59 La Nación, 11-2-1930. Además el diario da cuenta de la agitación política que existía en España en estas dos primeras semanas de febrero de 1930. 
jerarquía administrativa. Martínez Anido, en su calidad de ministro de Gobernación, siempre secundó estas decisiones de Primo de Rivera, aunque es difícil calibrar la influencia directa que tenía sobre el presidente. Por último, cabe señalar que a favor de los gobernadores civiles jugaba el hecho de que la mayoría provenían del funcionariado o de profesiones liberales, motivo por el que no necesitarían ninguna relación con el antiguo caciquismo provincial o local. Todo ello acrecentó la influencia y el poder del gobierno central sobre el resto de instituciones repartidas por el estado.

\section{CONCLUSIONES}

La ideología corporativa y castrense era una parte inherente del régimen político del general Primo de Rivera. El dictador no tenía una formación política sólida que le permitiera articular a las diferentes instituciones de la política española, excepto las fuerzas armadas y la Iglesia católica. En el caso valenciano en concreto, el modelo de organización militar se presentó como deseable en otros órdenes del ámbito civil. A pesar de lo cuestionable de sus decisiones, los dirigentes militares en la provincia, cualquiera que fuera su ámbito, estaban en una posición de fuerza que les permitía no dar ningún tipo de explicaciones acerca de su gestión, a excepción del dictador.

No obstante, tal y como hemos visto, la incertidumbre y el peligro en los primeros momentos del golpe militar conllevaron una serie de divisiones y diferencia de criterios en las élites de los cuarteles valencianos. Además, la ideología de los militares no era única, más bien se caracterizaba por una cierta pluralidad, acentuada por el conflicto entre junteros y africanistas que venía marcando la vida política española desde antes de la dictadura.

Según la ideología política de buena parte del estamento militar el Ejército era el defensor interno de la Patria. Para ello era necesario que se dotara a las diferentes provincias y regiones de unos funcionarios adictos al régimen. En aquellas instituciones que escapaban al control militar desde su creación, como eran los gobiernos civiles, el nuevo régimen estaba dispuesto a suprimir su carácter civil y otorgar su dirección a militares. El sistema de nombramientos favoreció la sumisión y la fidelidad al dictador. Como hemos visto la estructura tenía una forma piramidal y era el propio dictador el primer funcionario en disponer de sus propios colaboradores en el gobierno central. Pero no era suficiente, igualmente necesitaba representantes fieles en provincias. El grueso de estos representantes militares en Valencia los empezó a encontrar el día del golpe de estado. 


\section{BIBLIOGRAFÍA}

ALBA, V. (1981): Los conservadores en España, Barcelona, Editorial Planeta, 417 p. AUNÓS, E. (1944): Primo de Rivera, Soldado y gobernante, Madrid, Editorial Alhambra, 1944, 240 p.

BARRIO ALONSO, Á. (2006): "La oportunidad perdida: 1919, mito y realidad del poder sindical", Ayer, 63, 153-184.

BEN-AMI, S. (1984): La dictadura de Primo de Rivera: 1923-1930, Barcelona, Planeta, $325 \mathrm{p}$.

CABRERA, M. (dir.) (1998): Con luz y taquígrafos. El Parlamento en la Restauración (1913-1923), Madrid, Taurus, 388 p.

CABRERA, M. (2003): "El rey constitucional", en: Moreno Luzón, J. (Ed.), Alfonso XIII: un político en el trono, Madrid, Marcial Pons, 83-110.

CARNERO ARBAT, T. (1997): "Democratización limitada y deterioro político en España, 1874-1930”, en: Forner, S., Democracia, elecciones y modernización en Europa. Siglos XIX y XX, Madrid, Ediciones Cátedra, 203-240.

DEL REY REGUILLO, F. y MORENO LUZÓN, J. (1996): "Semblanza de la élite parlamentaria en la crisis de la Restauración (1914-1923)", Revista de estudios políticos, 93, 177-201.

GÓMEZ-NAVARRO, J. L. (1991): El régimen de Primo de Rivera: reyes, Dictaduras y Dictadores, Madrid, Ediciones Cátedra, 553 p.

GONZÁLEZ CALBET, M. T. (1987): La dictadura de Primo de Rivera: el directorio militar, Madrid, El Arquero, 290 p.

GONZÁLEZ CALLEJA, E. (1999): El máuser y el sufragio. Orden público, subversión y violencia política en la crisis de la Restauración (1917-1931), Madrid, Consejo Superior de Investigaciones Científicas, $719 \mathrm{p}$.

GONZÁLEZ CUEVAS, P. (2008): “Tradicionalismo, catolicismo y nacionalismo: la extrema derecha durante el régimen de la Restauración (1898-1930)", Ayer, 71, 25-52.

JULIÁ, S. (1999): Un siglo de España. Política y sociedad, Madrid, Marcial Pons, 304 p.

MARCO MIRANDA, V. (1975): Las conspiraciones contra la Dictadura (1923-1930), Madrid, Tebas, $206 \mathrm{p}$.

MARTORELL, M. y JULIÁ, S. (2012): Manual de historia política y social de España (1808-2011), Barcelona, RBA, 510 p.

MORENO LUZÓN, J. (2003): "El rey de papel: textos y debates sobre Alfonso XIII", en: Moreno Luzón, J. (Ed.), Alfonso XIII. Un político en el trono, Madrid, Cátedra-Marcial Pons, 23-58.

NAVAJAS ZUBELDIA, C. (1989): “Ejército y sociedad en España, 1923-1930”, Berсео, 116-117, 157-170.

NAVAJAS ZUBELDIA, C. (1992): Ejército, estado y sociedad en España (1923-1930), Logroño, Instituto de Estudios Riojanos, 314 p.

PAREDES ALONSO, F. J. (2004): Historia contemporánea de España, Barcelona, Ariel, 1138 p. 
PEMARTÍN, J. (1929): Los valores históricos de la dictadura española, Madrid, Junta de Propaganda Patriótica y Ciudadana, 696 p.

PÉREZ ORTIZ, J. F. (1990): La provincia de Alicante durante la Dictadura de Primo de Rivera: evolución política, Alicante, tesina del Diploma de Estudios Avanzados, $150 \mathrm{p}$.

PRESTON, P. (2006): Franco, Caudillo de España, Barcelona, Ediciones De Bolsillo, 1038 p.

QUIROGA FERNÁNDEZ DE SOTO, A. (2008): Haciendo españoles: la nacionalización de las masas en la dictadura de Primo de Rivera, Madrid, Centro de Estudios Políticos y Constitucionales, 384 p.

QUIROGA FERNÁNDEZ DE SOTO, A. (2013): “La construcción carismática del general Primo de Rivera”, Ayer, 91, 147-168.

SANTACREU SOLER, J. M. y PÉREZ HERRANZ, F. M. (2000): “La 'cuestión de España' a las puertas del siglo XXI”, Anales de Historia contemporánea, 16, 173-197.

SECO SERRANO, C. (2000): Historia del conservadurismo español. Una línea política integradora en el siglo XIX, Madrid, Ediciones Temas de Hoy, 343 p.

TRAVERSO, E. (2009): A sangre y fuego. De la guerra civil europea (1914-1945), Valencia, Publicacions Universitat de València, 267 p.

TUSELL, J. (1977): La crisis del caciquismo andaluz (1923-1931), Barcelona, Cupsa, $469 \mathrm{p}$.

TUSELL, J. (1987): Radiografía de un golpe de Estado. El ascenso al poder del general Primo de Rivera, Madrid, Alianza Editorial, 282 p.

TUSELL, J. y GARCÍA QUEIPO DE LLANO, G. (2001): Alfonso XIII, Madrid, Taurus, $765 \mathrm{p}$.

VÁZQUEZ DE PRADA, M. (2001): España 1900-2000. La conquista de la democracia, Pamplona, Ediciones Eunate, 344 p. 
CRONICA ACADEMICA 